\title{
ERODIBILIDADE DE SOLOS DERIVADOS DE ROCHAS DA SUÍTE SERRA DOS ÓRGÃOS: IMPLICAÇÕES PARA A INSTABILIDADE DE TALUDES DE CORTE
}

\author{
ERODIBILITY OF SOIL DERIVED FROM ROCKS OF THE SERRA DOS ORGÃOS SUITE: \\ IMPLICATIONS FOR THE INSTABILITY OF CUTTING SLOPES
}

\section{Rafael Santos de SOUSA, Helena POLIVANOV, Emílio Velloso BARROSO \\ Universidade Federal do Rio de Janeiro, Centro de Ciências Matemáticas e da Natureza. Instituto de Geociências, Departamento de Geologia. Avenida Athos da Silveira Ramos, 274 - Cidade Universitária - Ilha do Fundão, Rio de Janeiro - RJ. \\ E-mails: rafaelgeosousa@gmail.com, hpolivanov@gmail.com,emilio@geologia.ufrj.br}

\author{
Introdução \\ Características da Área de Estudo \\ Localização e ocupação da área de estudo \\ Geologia, Geomorfologia e Clima \\ Materiais \\ Métodos \\ Amostragem \\ Mineralogia \\ Propriedades físicas \\ Cisalhamento Direto \\ Resultados e discussões \\ Mineralogia \\ Propriedades físicas \\ Cisalhamento Direto \\ Conclusões \\ Referências
}

RESUMO - Problemas de instabilidade de taludes podem ser deflagrados por processos erosivos nos horizontes de solos saprolítcos. Nesses casos, a identificação das causas e a análise dos processos instabilizadores pode não ser uma tarefa trivial. Embora a associação dos processos de deslizamento e erosão seja relativamente comum, nem sempre as relações entre causa e efeito são bem definidas, podendo impactar significativamente os custos dos projetos e obras de instabilização. Portanto, ainda é necessário avançar na identificação prévia das erodibilidades dos solos saprolíticos, os quais em condições críticas podem deflagrar a instabilidade dos horizontes superiores do solo. O principal objetivo desse manuscrito é avaliar índices que auxiliem na previsão da erodibilidade de solos saprolíticos e seu potencial na deflagração de processos de movimentos de massa em encostas ou taludes instáveis. Foram selecionados para análises dois perfis de solo, incluindo o solo saprolítico e os horizontes pedológicos, derivados de rochas da Suíte Serra dos órgãos e com registro de instabilidades e evidencias de feições erosivas observadas em campo, no município de São João de Meriti (RJ). Após a amostragem, os horizontes pedológicos e saprolíticos de cada perfil foram analisados quanto à mineralogia, propriedades físicas e mecânicas. Os resultados obtidos em laboratório confirmam as observações de campo quanto à elevada erodibilidade do solo saprolítico e seu potencial para deflagração de rupturas dos taludes de corte na região. Esse conhecimento fundamental é útil para assistir às autoridades municipais quanto ao uso do solo urbano, em especial, para a necessidade de se evitar cortes profundos e assim manter a preservação dos horizontes saprolíticos e o equilíbrio das encostas.

Palavras-chave: Instabilidade de talude. Deslizamentos. Erodibilidade.

ABSTRACT - Hillslope instability issues can be triggered by erosion processes in residual soil horizons. Identifying the causes and analysing these processes may not be a trivial task. Although the association between sliding and erosion is relatively frequent, causes and effects relationships are not always well defined and can hugely impact budgets of projects and works. Therefore, it is still necessary to go forward in foresee the erodibility of residual soils, which under critical conditions may drive to the instability of above soil horizons. The main purpose of this manuscript is to evaluate indices to support the erodibility forecast of residual soils and their potential to initiate landslides on hillslopes. Initially two profiles of residual soils were chosen both located at São João do Meriti and developed over rocks of Serra dos Orgãos suite. They were chosen based on evidences of erosive features and records of landslides. After sampling, the residual and pedological horizons were analysed regarding its mineralogy, physical indices and mechanical properties. Results have confirmed the field observations related to the high erodibility of residual horizons and its ability to initiate instability processes in the cut slopes in the municipality. This fundamental knowledge is helpful to assist the government authorities regarding the soil use and mainly for the need of avoiding deep cuts in slopes and then keep up the preservation of residual horizons and the safe equilibrium of hillslopes.

Keywords: Hillslope. Landslides. Erodibility.

\section{INTRODUÇÃO}

Processos erosivos e escorregamentos em encostas ocorrem largamente em todo o território brasileiro e anualmente causam prejuízos governamentais. Esses processos também frequentemente se configuram em desastres e expressiva ocorrência no Brasil. Segundo o 
Nacional (Brasil, 2013) sobre os desastres ocorridos no Brasil, as erosões e os movimentos de massa em encostas aumentaram mais de 9 e 21 vezes, respectivamente, quando comparadas as décadas de 1990 e de 2000 . Ainda segundo a mesma fonte, nas duas décadas abordadas no estudo, os movimentos de massa em encostas foram responsáveis por $15,6 \%$ dos óbitos em eventos de desastres naturais no país. Esse índice é menor apenas que o de óbitos verificados para as enxurradas.

As razões que levam aos cenários de perigo nas encostas brasileiras são diversas e estão associadas à geologia (tipos de solo, de rochas, a resistência dos geomateriais, o arcabouço estrutural local, o relevo e a hidrologia subterrânea), aos eventos meteorológicos extremos, às condições inadequadas das ocupações (cortes executados sem critérios técnicos, adensamento populacional exageradamente alto, padrões construtivos de baixa qualidade e ausência das infraestruturas básicas ou implantação parcial das mesmas), à educação relacionada à percepção do risco pela população e à condição socioeconômica de parte significativa da população brasileira que busca para sua moradia, terrenos mais baratos e, muitas vezes, de maior fragilidade frente aos processos geológicos da dinâmica superficial.

Nesse contexto, nas últimas décadas o município de São João de Meriti sofreu uma intensa expansão urbana, sem o necessário planejamento adequado do uso do solo. A ocupação característica das encostas, com construções sem os requisitos técnicos mínimos, associada à falta de percepção de risco da população e a condição social existente criaram um cenário de vulnerabilidade na cidade, potencializando os perigos e riscos relacionados aos movimentos gravitacionais de massa. Pelas razões expostas a cidade de São João de Meriti foi relacionada pela Secretária Nacional de Proteção e Defesa Civil entre os 821 municípios brasileiros prioritários no que tange às ações relacionadas à gestão de risco.

Um dos principais processos observados nas inspeções de campo e atrelado às rupturas das encostas ocupadas no município de São João de Meriti está relacionado com a erosão prévia dos solos saprolíticos que levam à instabilidade dos horizontes mais superficiais dos solos.

A associação entre processos de erosão e de deslizamentos de solos tem sido abordada de diferentes formas na literatura. Muitas vezes esses processos são tratados em conjunto quando o interesse do estudo está associado com a evolução da paisagem através da denudação do relevo (Chen et. al., 2015) e com a geração de sedimentos (Betts et al., 2017). Contudo na escala adequada para fins das análises de estabilidade das encostas, os processos de erosão e de deslizamentos devem ser diferenciados, embora nem sempre seja fácil separar onde o primeiro se inicia e o segundo é deflagrado. A associação entre erosão e escorregamento tem sido relatada na literatura técnica nos casos em que os deslizamentos formam barramentos em rios e o processo de erosão destes corpos pode levar a inundações (Fan et al., 2018). Nesse caso particular, o deslizamento ocorre antes e a erosão é cronologicamente posterior, atua sobre o material mobilizado da encosta e coloca em risco o barramento artificial, por exemplo, através de processos de piping (Wang et al., 2018).

A relação entre erosão subterrânea e processos de creep em encostas foi descrita por (Furuya et al.,1999) para solos derivados de xistos no Japão. Segundo os autores a massa de solo movimentada aumenta a suscetibilidade à erosão, enquanto a erosão subterrânea, por sua vez, causa as instabilidades da massa de solo. Essa relação entre processos erosivos e instabilidade de encostas foi também pontuada por (RadbruchHall \& Varnes, 1976), para o desenvolvimento de mecanismos mais complexos de ruptura (rupturas progressivas) e como esses processos podem levar restrições às atividades de engenharia.

No Brasil há alguns estudos específicos relacionados aos processos erosivos como deflagradores de rupturas em encosta. É possível citar o trabalho de (Soares et al., 2018) que enfocou a instabilidade de taludes de rodovias não pavimentadas na região serrana do município do estado do Rio de Janeiro, provocada pela erosão inicial dos saprolitos (horizontes C) de latossolos e argissolos. Um artigo como o mesmo enfoque, apresentado por (Moreira \& Polivanov, 2018), tratou também dos solos saprolíticos e dos horizontes pedológicos expostos em cortes de estrada na bacia do Sana, estado do Rio de Janeiro. Nesse caso, os autores também determinaram maiores erodibilidades nos solos saprolíticos que resultaram em instabilidades observadas em diversos pontos ao longo da estrada. 
Dessa forma, as erodibilidades relativas dos solos saprolíticos e dos horizontes pedológicos parecem controlar eventos de deslizamento ou queda de solos em taludes de cortes ou encostas naturais, mas principalmente no primeiro caso, onde há exposição dos saprólitos.

Nesse sentido, a Tabela 1 apresenta uma coletânea de propostas de diversos autores para índices de erodibilidade de solos, os quais levam em consideração diferentes parâmetros do solo. Tendo em vista as particularidades típicas dos solos formados em ambiente tropical, sobretudo a mineralogia, a papel da cimentação por sesquióxidos de ferro e a aglomeração de partículas finas, quando comparado aos solos clássicos da mecânica dos solos, derivados de sedimentos e formados em condições de clima temperado, neste trabalho deu-se preferência aos índices de erodibilidade propostos por autores brasileiros.

Além dos índices apresentados na tabela 1, baseados na granulometria e nos limites de consistência dos solos, (Bastos, 1999) propôs um índice de erodibilidade baseado na variação porcentual da coesão $(\Delta C)$, obtida em ensaios de cisalhamento direto com as amostras nos estados inundado $\left(C_{\text {inu }}\right)$ e na umidade natural de campo $\left(C_{\text {nat }}\right)$, conforme apresentado na equação 1 . Segundo o autor, solos que apresentam variações porcentuais da coesão iguais ou superiores a $85 \%$ devem ser considerados potencialmente erodíveis.

$$
\Delta C(\%)=\frac{C_{n a t}-C_{i n u}}{C_{n a t}} \times 100(1)
$$

No estudo apresentado nesse artigo foram avaliados diversos índices de erodibilidade e os mesmos foram comparados para solos saprolíticos formados a partir de rochas da Suíte Serra dos Órgãos e dos horizontes B de solos maduros.

Para tal foram selecionados dois taludes de corte em solo, que possuem histórico de rupturas do tipo planar, ambos localizados no bairro de Coelho da Rocha, em São João de Meriti, município da Baixada Fluminense, Região Metropolitana do Rio de Janeiro.

O objetivo é conhecer os melhores índices de erodibilidade que possam ser empregados para a possível previsão de rupturas em taludes de corte deflagradas pela erosão dos horizontes de solos saprolíticos.

Tabela 1 - Classificações de erodibilidade com base nos índices de consistência e granulometria.

\begin{tabular}{|c|c|c|}
\hline Parâmetros & Autor & Índices de Consistência \\
\hline \multirow{4}{*}{$\begin{array}{l}\text { Índices de } \\
\text { Consistência }\end{array}$} & Meireles (1967) & IP $<=8 \%$ e $\mathrm{LL}<=21 \%$ (fortemente erodível) \\
\hline & Bastos (1999) & IP $<10 \%$ (potencialmente erodíveis) \\
\hline & Santos e Castro (1967) & LL< $=50 \%$ e IP próximo a $20 \%$ (potencialmente erodíveis) \\
\hline & Santos (2001) & $\begin{array}{l}\text { IP }>15 \text { (boa resistência à erosão); } 6<\mathrm{IP}<15 \text { (média resistência à erosão); } \\
\text { IP }<6 \text { (baixa resistência à erosão) }\end{array}$ \\
\hline \multirow[b]{2}{*}{ Granulometria } & Bastos (1999) & $\%$ passante na peneira $\# 200<55 \%$ (solos potencialmente erodíveis) \\
\hline & Fragassi (2001) & $\begin{array}{l}\% \text { silte }+\% \text { areia fina relativamente elevada em relação à \% argila }+\% \\
\text { areia grossa (mais erodível) }\end{array}$ \\
\hline \begin{tabular}{c|} 
Índices de \\
Consistência e \\
Granulometria
\end{tabular} & Alcântara (1997) & $\begin{array}{c}\text { IP }<5 \% \text { e } 0 \%<\% \text { passante na peneira } \# 200<30 \% \text { (alta erodibilidade) } \\
5 \%<=\text { IP }<=15 \% \text { e } 30 \%<=\% \text { passante na peneira } \# 200<=60 \% \text { (média } \\
\text { erodibilidade) e IP }>15 \% \text { (baixa erodibilidade). }\end{array}$ \\
\hline
\end{tabular}

\section{CARACTERÍSTICAS DA ÁREA DE ESTUDO}

A seguir são apresentados aspectos da área de estudo, para fornecer ao leitor uma caracterização básica do município de São João de Meriti.

\section{Localização e ocupação da área de estudo}

O município de São João de Meriti está localizado a $22^{\circ} 47^{\prime} 48^{\prime \prime}$ de latitude $\mathrm{S}$ e a $43^{\circ} 23^{\prime} 48^{\prime \prime}$ de longitude O. Pertence a região metropolitana do Estado do Rio de Janeiro, sendo um dos treze municípios que formam a Baixada Fluminense.
Faz limites com os municípios do Rio de Janeiro, Duque de Caxias, Belford Roxo, Mesquita e Nilópolis.

De acordo com o censo do IBGE (2010), possui uma população estimada de 469.827 habitantes, numa área territorial de $34,5 \mathrm{~km} 2$, resultando na cidade de maior densidade demográfica do Brasil.

A cidade é dividida em 16 bairros, sendo o de Coelho da Rocha, aquele onde estão localizados os taludes de solo estudados nesse trabalho (Figura 1). 


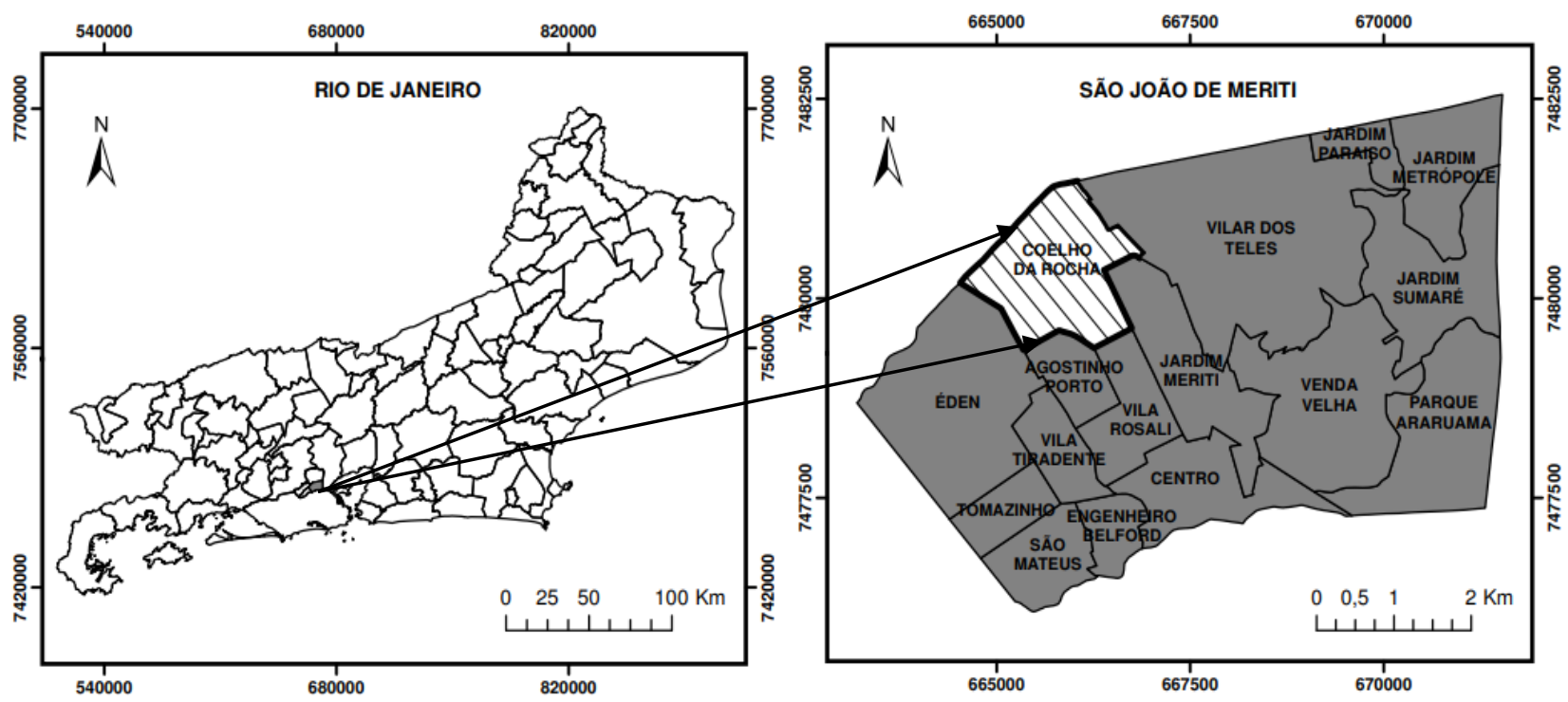

Figura 1 - Localização do Município de São João de Meriti, com destaque para o bairro da área de estudo hachurado. Imagens fornecidas pela Secretaria Municipal de Ambiente e Sustentabilidade da Prefeitura de São João de Meriti.

O padrão de urbanização é de lotes e quadras bem definidos na região central e de núcleos desordenados no restante do município, muitas vezes sobre as encostas dos morros e morrotes e planícies fluviais, predominando o padrão de moradias de média e baixa renda e de autoconstrução.

Por se tratar de um município totalmente urbano, o solo encontra-se na sua maior parte impermeabilizado por intervenções antrópicas diversas. Sendo assim, existem poucas áreas naturais em que possam ser feitos os reconhecimentos das características geológicas locais.

$\mathrm{O}$ crescimento acelerado e desordenado do município (Figuras 2A, 2B, 3A e 3B) resultou na ocupação inadequada nas áreas de encostas e de planícies fluviais.

Essas áreas apresentam hoje risco, respectivamente, de escorregamentos e inundações por conta dos fatores naturais e pelo padrão de ocupação desordenado (adaptado do PMRR, 2013).

\section{Geologia, Geomorfologia e Clima}

O município de São João de Meriti encontra-se inserido na unidade tectono-sedimentar chamada Gráben da Guanabara. O Gráben da Guanabara foi definido por (Almeida, 1976) que o denominou Rift da Guanabara, englobando toda a área de relevo deprimido que se estende desde a Baía de Sepetiba, a oeste, até a localidade de Barra de São João, a leste, no Estado do Rio de Janeiro.

Geologicamente o município de São João de Meriti se estabeleceu sobre o embasamento neoproterozoico constituído por rochas do complexo Rio Negro, representadas por gnaisses mesocráticos de composição quartzo diorítica a diorítica, intensamente deformados e migmatizados, de aspecto geralmente bandado e pelas litologias da Suíte Serra dos Órgãos, constituída por ortognaisses graníticos a granodioríticos foliados, de granulação grossa, de cor branca a cinza claro, resultantes do Ciclo Orogênico Brasiliano II (790-600 Ma) e III (570$560 \mathrm{Ma}$ ), respectivamente. Os blocos do embasamento cristalino, tectonicamente rebaixados por falhas normais, foram parcialmente ou totalmente recobertos por sedimentos colúvioaluvionares quaternários. Localmente essas litologias encontram-se bastantes intemperizadas, sendo encontradas em campo mais comumente como solos residuais maduros, na forma de saprólitos e mais raramente rocha sã (Silva \& Cunha, 2001).

A geomorfologia do município de São João de Meriti é composta, basicamente por colinas residuais isoladas, com vertentes convexas, topos arredondados e baixos (geralmente inferiores a 100 metros), entremeados por planícies colúvioaluvionares, naturalmente mal drenadas, compostas por solos argilo-arenosos e/ou solos argilosos orgânicos (Dantas, 2000).

De acordo com o Mapa de Clima do Brasil (IBGE, 2002) o município de São João de Meriti se localiza em sua totalidade na classificação de Tropical Quente Úmido, com média anual de temperatura acima de $18^{\circ} \mathrm{C}$, chuvas concentradas nos meses de verão (dezembro, janeiro, fevereiro e março) e média pluviométrica entre 1.000 a 1.500 $\mathrm{mm}$ anuais 

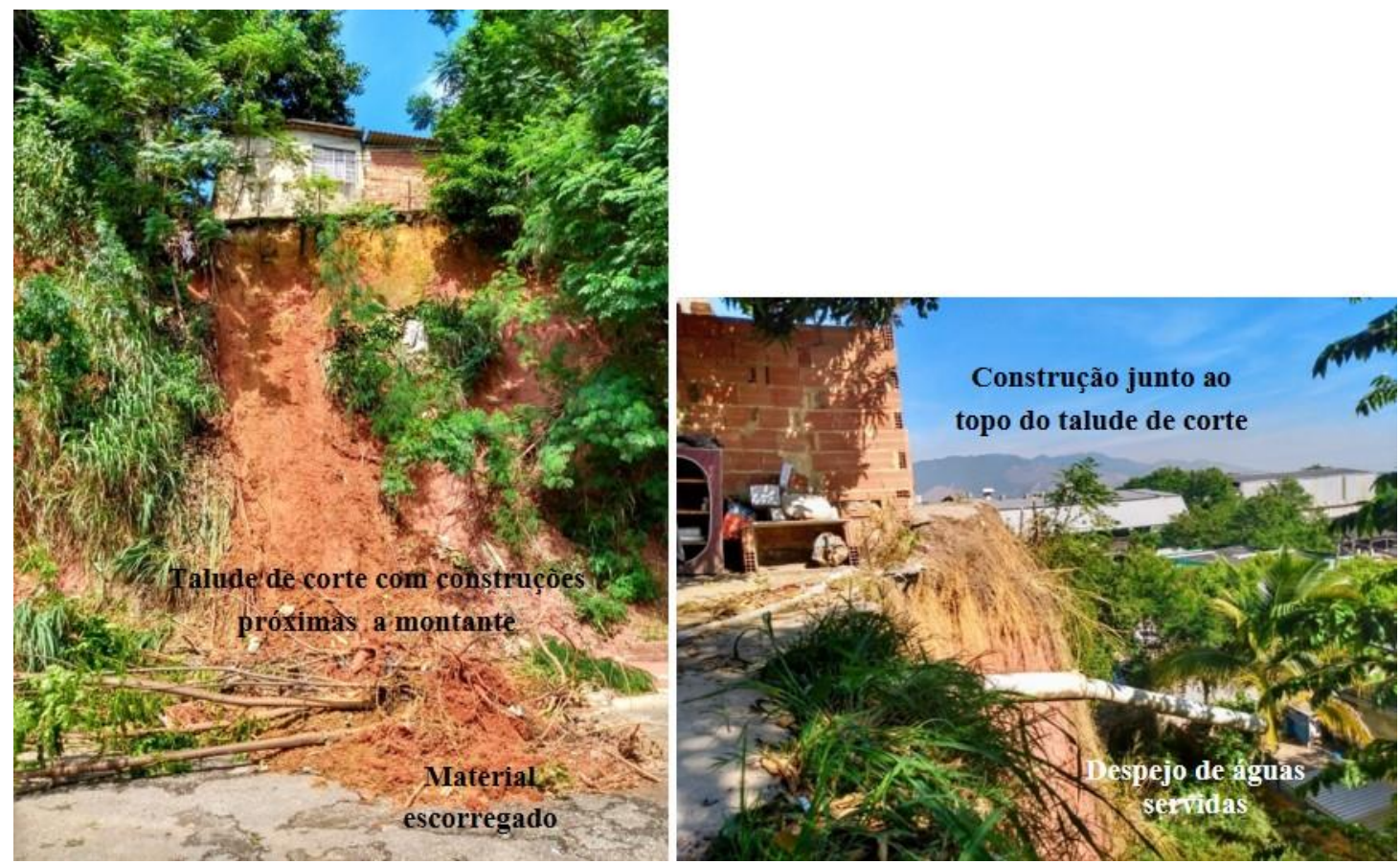

Figuras 2 - Construções a montante e a jusante do talude da Vigilância Sanitária com observação de escorregamento.
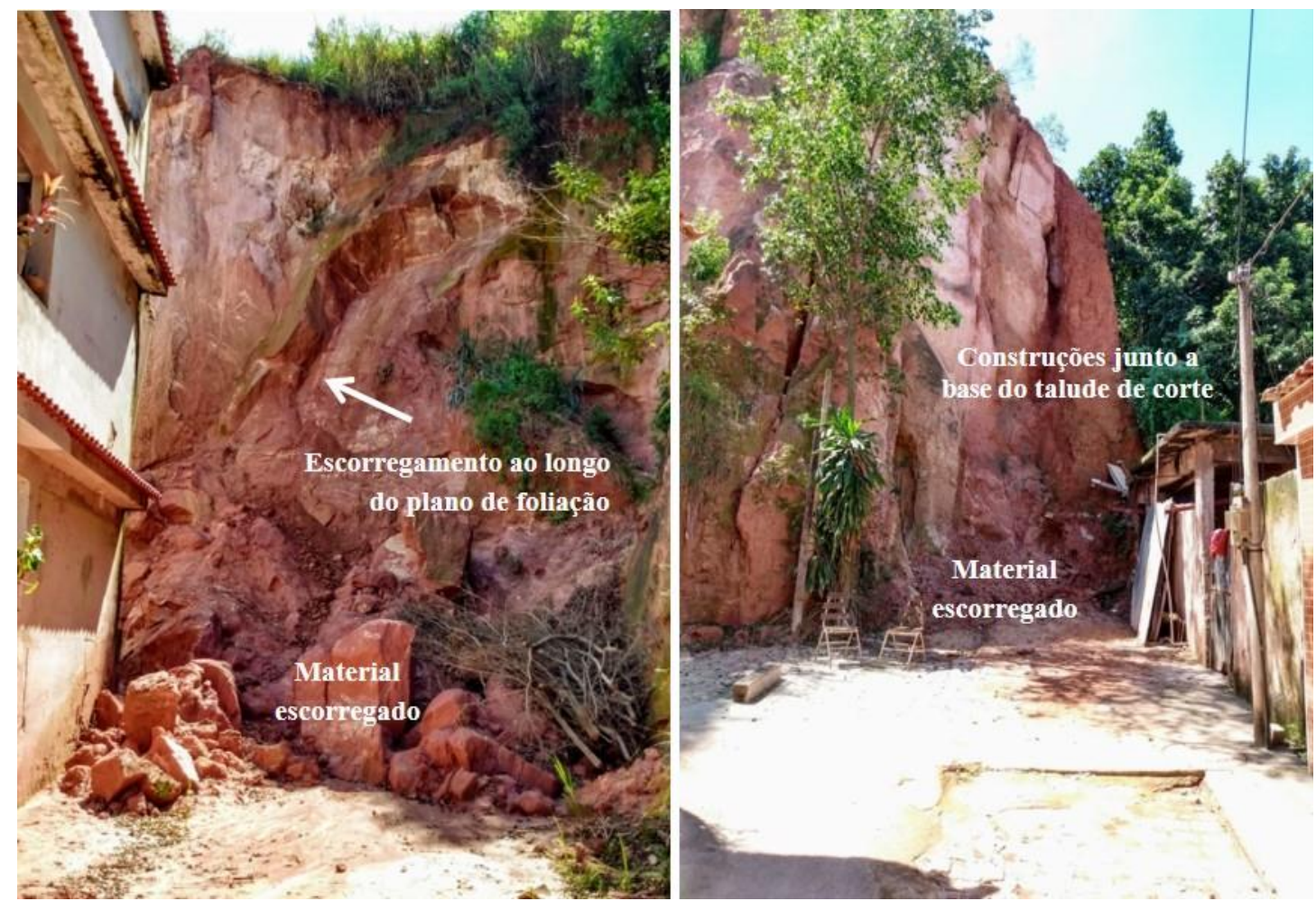

Figuras 3 - Construções próximas da base do talude da Rua da Ligação com observação de escorregamento ao longo do plano de foliação.

\section{MATERIAIS}

Previamente a coleta dos solos, campanhas de campo foram realizadas para a avaliação dos perfis existentes na área de estudo. A finalidade inicial foi identificar os locais com os acessos mais favoráveis para o trabalho de descrição e amostragem. Além da logística, outros critérios técnicos também governaram a escolha do local de amostragem: perfil de solo completo (exibindo o material de origem, horizonte saprolítico, e os horizontes pedológicos), local de alta intervenção antrópica, com taludes de corte expondo processos erosivos em locais com registros de instabilidade.

Dois locais foram escolhidos para as amostragens por satisfazerem as condições descritas acima. A tabela 2 informa os locais e 
os perfis de solo passam a ser denominados nesse trabalho pelo nome do local e da rua e pelo horizonte em que foram coletados. $\mathrm{Na}$ referida tabela os horizontes $\mathrm{C}$ correspondem aos solos saprolíticos.

A figura 4 ilustra o posicionamento dos perfis estudados nas ruas do bairro de Coelho da Rocha. Nesses locais foram coletadas amostras com a estrutura do solo não preservada (deformadas) e com a estrutura preservada (não deformadas). As análises realizadas com cada tipo de amostra serão apresentadas na seção sobre os métodos.

Tabela 2 - Localização das amostras coletadas de acordo com a profundidade.

\begin{tabular}{c|c|c|c}
\hline \multirow{2}{*}{ Talude } & \multirow{2}{*}{ Coordenada GPS } & \multirow{2}{*}{ Horizonte } & Profundidade (m) \\
\hline \multirow{2}{*}{ Vigilância Sanitária } & \multirow{2}{*}{$0665079 / 7480506$} & $\mathrm{~B}$ & 1 \\
\cline { 3 - 4 } & & $\mathrm{C}$ & 8 \\
\hline \multirow{2}{*}{ Ligação } & \multirow{2}{*}{$0666413 / 7480980$} & $\mathrm{~B}$ & 8 \\
\cline { 3 - 4 } & & $\mathrm{C}$ & 6 \\
\hline
\end{tabular}

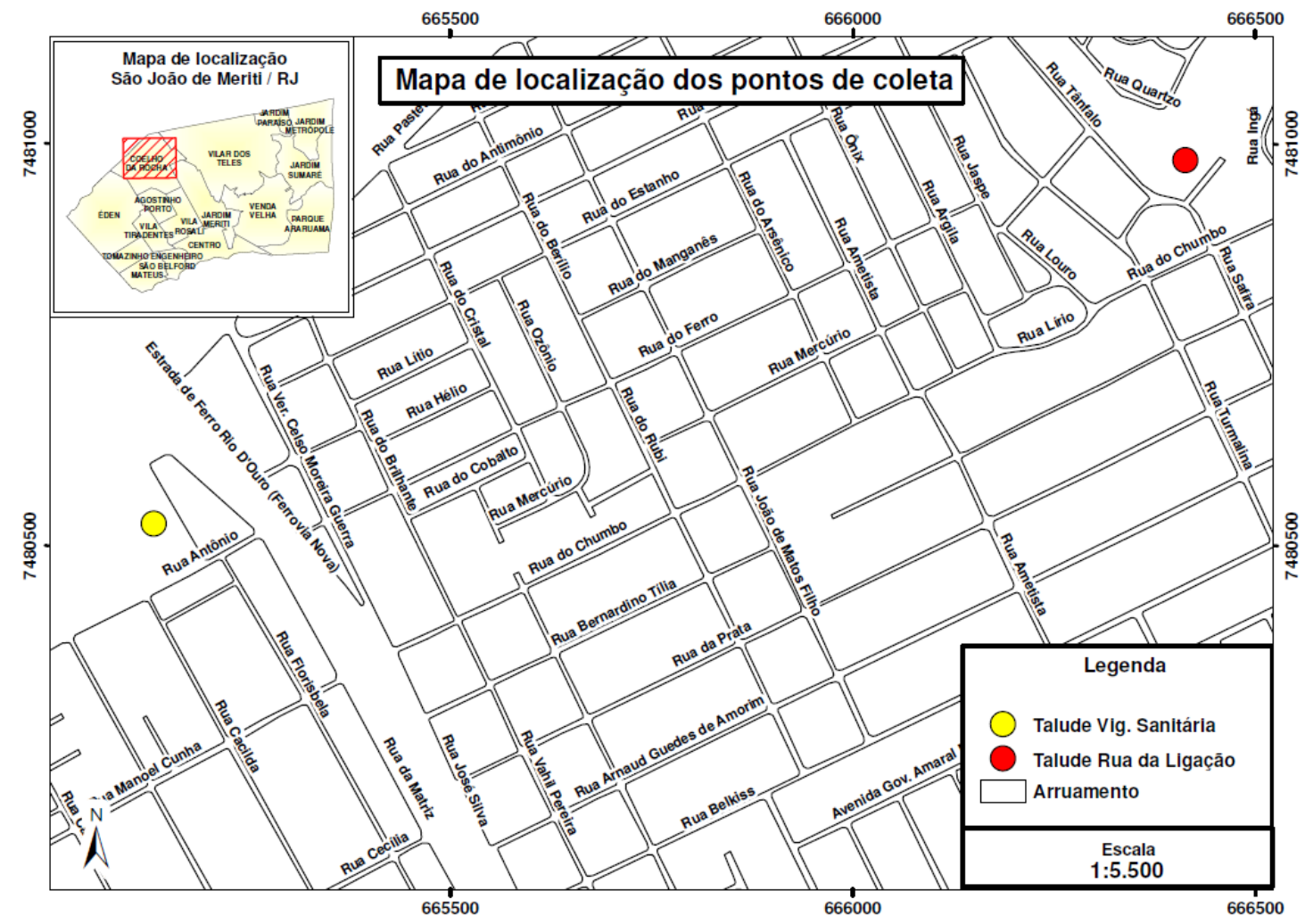

Figura 4 - Mapa de Localização dos pontos de coleta das amostras deformadas e indeformadas. Imagem fornecida pela Secretaria Municipal de Ambiente e Sustentabilidade da Prefeitura de São João de Meriti.

No campo foi observado que os horizontes B pedológicos, em ambos os perfis, encontram-se em avançado estágio de intemperização, e com quase todos os minerais primários em completa alteração. Macroscopicamente somente o quartzo pode ser identificado. Tais horizontes são bastante desenvolvidos e lixiviados, não apresentando estruturas da rocha original. De acordo com a carta de cores de Munsell, estes horizontes variam de amarelo-brunado, para o talude da Vigilância Sanitária e amarelo-avermelhado para a rua da Ligação (Figuras 5A, 5B).

Os horizontes de solos saprolíticos (horizonte C), possuem estruturas herdadas da rocha original. Dentre as estruturas, foram observados bandamentos gnáissicos e veios de quartzo. Esses horizontes foram originados da alteração de rochas gnáissicas, proveniente da Suíte Serra dos Órgãos.

Nesses horizontes, além do quartzo, podem ser observados em campo minerais primários de mica do tipo muscovita e pequenas quantidades de minerais magnéticos ferrosos. Ao longo desses corpos é possível notar preenchimentos de minerais secundários esbranquiçados, provavelmente produtos de alteração dos feldspatos (Figura 5C). A passagem do horizonte $\mathrm{C}$ para o horizonte $\mathrm{B}$ se dá de maneira gradual (Figura 6). De acordo com a carta de cores de Munsell, a coloração destes horizontes é vermelho-claro acinzentado. 

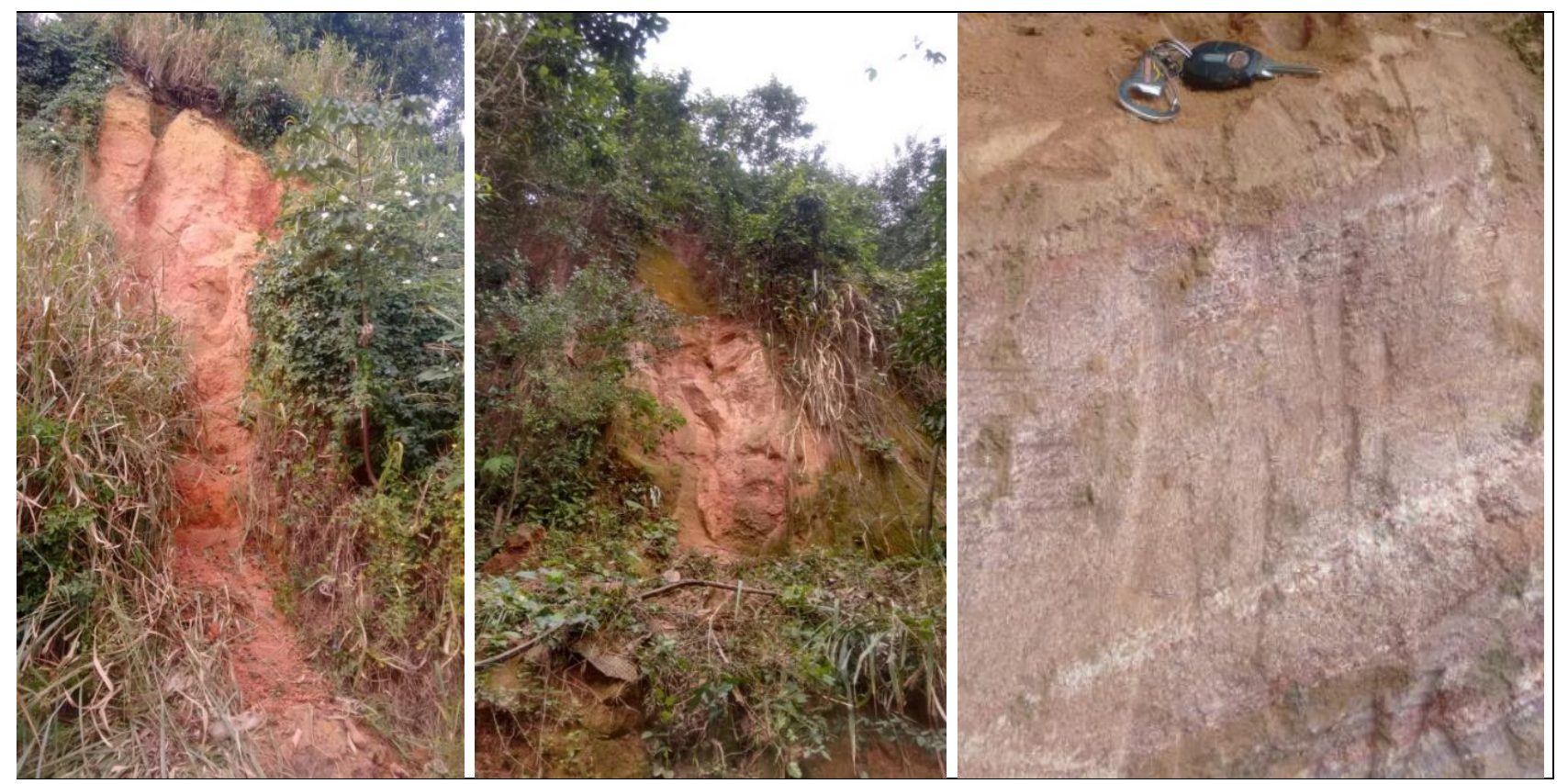

Figuras 5 - A e B) Aspecto geral dos perfis de solos da Vigilância Sanitária e da Rua Ligação, respectivamente. C) Horizonte $\mathrm{C}$ residual (solo saprolítico), com minerais secundários esbranquiçados e vestígios de estruturas reliquiares.

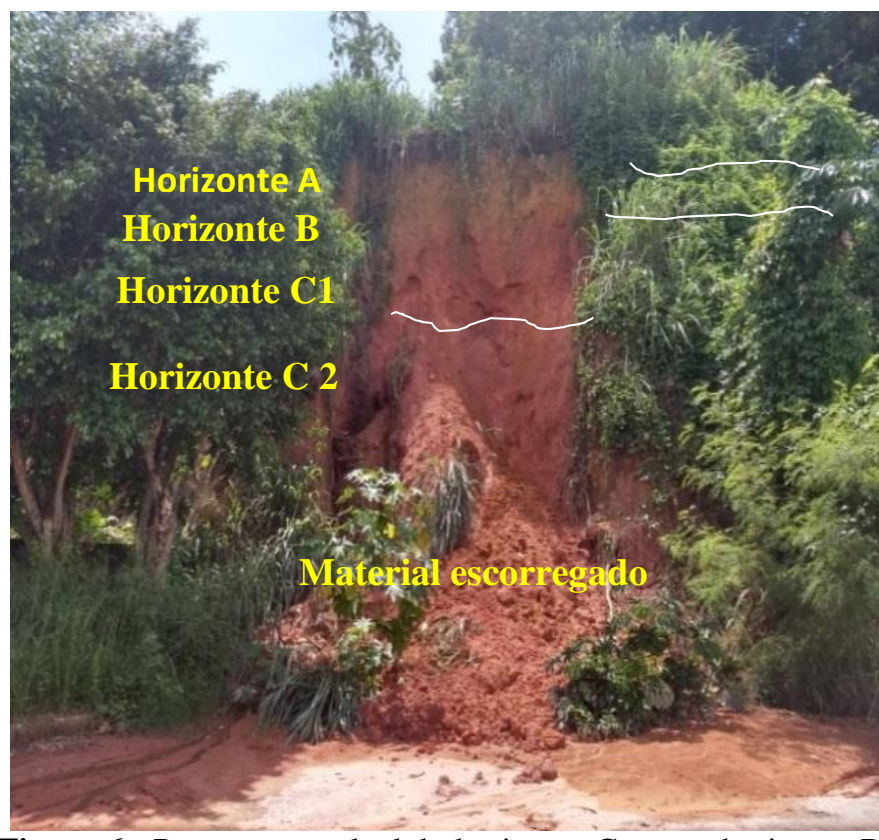

Figura 6 - Passagem gradual do horizonte C para o horizonte B.

\section{MÉTODOS}

Nesta seção os métodos de amostragem do solo e os métodos analíticos utilizados nessa pesquisa são apresentados para definir as técnicas empregadas.

\section{Amostragem}

O processo de amostragem dos solos seguiu as recomendações preconizadas pela NBR 9604 (ABNT, 2016c) e resultou em dois conjuntos distintos de amostras: deformadas e indeformadas (Figura 7).

As amostras deformadas são retiradas por escavação do talude, procedimento que não preserva a estruturação interna do solo e altera as condições iniciais de consistência. O volume de solo coletado para cada horizonte alcançou massa de 3,0 kg para cada horizonte. Todas as amostras foram acondicionadas em sacos plásticos para manutenção da umidade de campo e foram devidamente identificadas.

As amostras indeformadas são extraídas esculpindo-se blocos de solo, procurando preservar a estrutura interna e umidade do material parental. Esses foram coletados em blocos cúbicos (dimensões $30 \mathrm{~cm}$ x $30 \mathrm{~cm}$ x 30 $\mathrm{cm})$ para cada horizonte, posteriormente recobertos com filme de PVC, papel alumínio e 
tecido de morim e, então, recobertos com parafina líquida.

Após o endurecimento da parafina, as amostras indeformadas foram acondicionadas em caixas de madeira, preenchidas com serragem para permitir o transporte seguro até o laboratório. Todas as caixas foram devidamente identificadas.
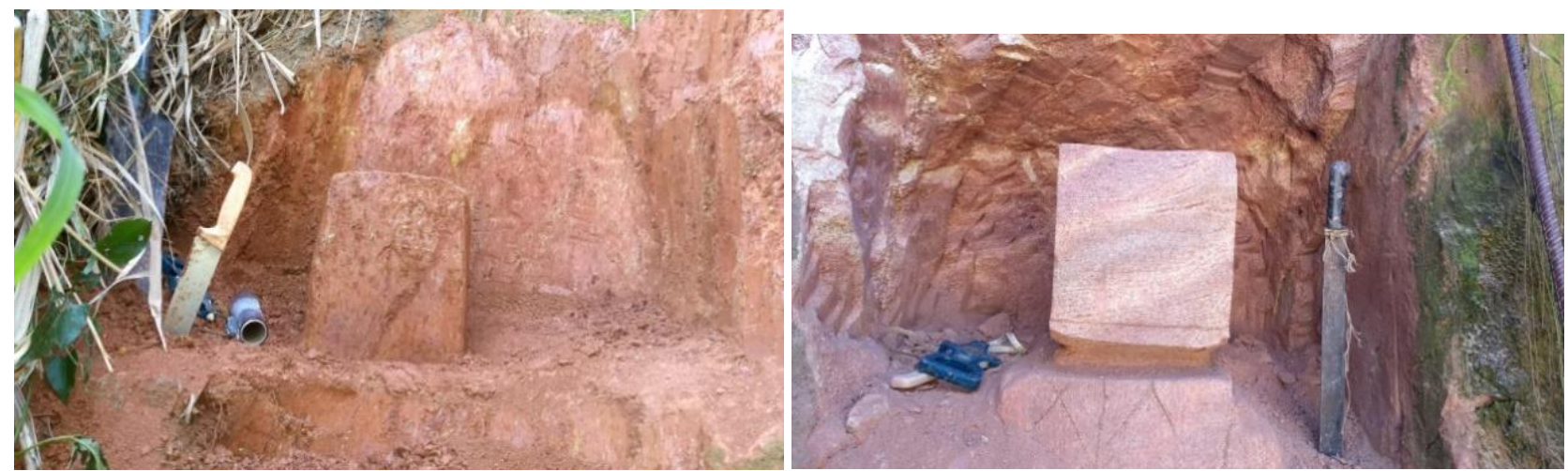

Figura 7- Retirada das amostras indeformadas dos horizontes C, dos taludes da Vigilância Sanitária e da Rua da Ligação, respectivamente. Destaque para a estrutura do solo.

\section{Mineralogia}

As caracterizações mineralógicas foram realizadas pelo método da difração de raios-X (DRX), após a separação da fração argila do solo pelo processo de sedimentação. A preparação das amostras para a obtenção da fração argila e a confecção das lâminas, seguiram os procedimentos propostos por (Jackson, 1969). As análises por DRX foram feitas nas condições natural (com e sem ferro), conforme (Mehra \& Jackson, 1960). Em seguida as lâminas previamente preparadas foram submetidas à atmosfera saturada por etileno glicol com o objetivo de identificar possíveis minerais expansivos. E por fim, na terceira fase de preparação das lâminas, estas foram aquecidas em forno-mufla a $500^{\circ} \mathrm{C}$ com o propósito de investigar o colapso e/ou destruição da estrutura dos argilominerais e para fins comparativos com as outras condições citadas.

\section{Propriedades físicas}

A análise granulométrica foi realizada através do peneiramento das frações grossas e sedimentação das frações finas, com leitura da densidade da solução, conforme procedimentos recomendados na norma NBR 7181 (ABNT, 2017b).

O grau de floculação e de dispersão foram determinados conforme Embrapa (2017).

A massa específica dos grãos, massa específica natural e o teor de umidade foram determinados conforme estabelecem, respectivamente, as normas NBR 6508 (ABNT, 1984), NBR 9813 (ABNT, 2016d) e NBR 6457 (ABNT, 2016a).

Os ensaios dos limites de consistência, limites de liquidez (LL) e plasticidade (LP), foram executados de acordo com o prescrito nas normas NBR 6459 (ABNT, 2017a) e NBR 7180 (ABNT, 2016b), respectivamente.

Através da análise conjunta dos dados de granulometria e do IP (diferença entre os valores de LL e LP) é possível determinar o Índice de Atividade (Ia), pela relação entre o IP sobre o percentual de argila (fração $<2 \mu$ ), conforme (Skempton, 1953). Deve-se mencionar também que com os dados de distribuição granulométrica, LL e LP, os solos estudados foram classificados segundo o Sistema Unificado de Classificação do Solos (SUCS). Embora muitas vezes o sistema SUCS receba críticas quanto a sua aplicação para previsão do comportamento de solos desenvolvidos em climas tropicais, optou-se pela sua utilização nessa pesquisa tendo em vista sua tradição de uso na área da Geologia de Engenharia.

Por fim foi calculada a razão silte/argila, com o objetivo de se avaliar o estágio de intemperismo dos solos estudados. De acordo com o Sistema Brasileiro de Classificação de Solos, os solos de textura média, com valores inferiores a 0,7 são considerados solos bastante intemperizados (EMBRAPA, 2013).

Outros índices físicos, como a porosidade e o índice de vazios, foram calculados a partir dos demais índices obtidos experimentalmente.

\section{Resistência ao cisalhamento}

Os ensaios de cisalhamento direto têm como objetivo a construção da envoltória de resistência de Mohr-Coulomb e a determinação dos parâmetros de resistência do solo, a coesão e o ângulo de atrito. 
Para a execução dos ensaios foram observados os procedimentos recomendados na norma D3080 (ASTM, 1990). Os ensaios foram realizados com o solo na umidade natural e na condição inundada. Em ambas as condições, adotou-se a velocidade de cisalhamento de 0,012 $\mathrm{mm} / \mathrm{min}$ para garantir que na condição inundada a poropressão gerada pudesse ser dissipada, uma vez que estas não são mensuradas durante o ensaio.

Tabela 3 - Tensões aplicadas nos ensaios de cisalhamento para os horizontes pedológicos e saprolíticos.

\begin{tabular}{|c|c|c|c|c|c|c|}
\hline \multirow{2}{*}{ Talude } & \multirow{2}{*}{ Horizonte } & \multirow{2}{*}{$\Upsilon_{n a t}\left(\mathrm{kN} / \mathrm{m}^{3}\right)$} & \multirow{2}{*}{$\mathbf{Z}(\mathbf{m})$} & \multicolumn{3}{|c|}{ Tensões Normais (kPa) } \\
\hline & & & & $\sigma_{\min }$ & $\overline{\sigma_{r e f}}$ & $\overline{\sigma_{\max }}$ \\
\hline \multirow{2}{*}{ Vigilância Sanitária } & $\mathrm{B}$ & 17,9 & 1 & 8,9 & 17,9 & 26,9 \\
\hline & $\mathrm{C}$ & 17,8 & 8 & 71,3 & 142,5 & 213,8 \\
\hline \multirow{2}{*}{ Ligação } & $\mathrm{B}$ & 19,2 & 0,6 & 5,8 & 11,5 & 17,3 \\
\hline & $\mathrm{C}$ & 16,01 & 8 & 64 & 128,1 & 192,1 \\
\hline
\end{tabular}

Para cada horizonte de solo, os ensaios foram programados com três tensões normais para a construção da envoltória de Mohr-Coulomb. A tensão normal tomada como referência é sempre a intermediária e é determinada pelo produto da profundidade de amostragem do horizonte de solo pelo peso específico natural $\left(\gamma_{\text {nat }}\right)$ do solo. As outras duas tensões normais, a mínima e a máxima do ensaio, foram adotadas

\section{RESULTADOS E DISCUSSÕES}

\section{Mineralogia}

Os resultados da análise mineralógica por difração de raios $\mathrm{X}$ são apresentados nas figuras 8A, 8B, 8C, 8D.

As curvas pretas representam a condição natural, as curvas azuis a condição saturada com etileno glicol e a curva vermelha a condição aquecida.

Os resultados das análises realizadas por DRX mostram que a fração argila dos solos estudados é composta principalmente pelo argilomineral caulinita. A presença da caulinita demonstra solos bastantes intemperizados e lixiviados devidos estarem submetidos ao clima tropical, quente e úmido. A presença de traços de Ilita no horizonte $\mathrm{C}$, da rua da Ligação provavelmente deve estar relacionada com a intemperização das micas, as quais se apresentam em maiores concentrações nos solos mais jovens, conforme aponta (Ernani, 2008).

Pode-se afirmar também que os solos estudados não apresentam marcantes diferenças mineralógicas entre si e nem mesmo internamente, entre os horizontes. Em outras palavras, todos os horizontes estudados caracterizam-se por forte homogeneidade mineralógica.

\section{Propriedades físicas}

Os resultados da caracterização física, dos multiplicando-se a tensão normal de referência, respectivamente, por 0,5 e 1,5. A Tabela 3 resume as tensões normais aplicadas em cada ensaio de cisalhamento direto.

A obtenção dos parâmetros de resistência dos solos com o ensaio de cisalhamento direto teve por finalidade a aplicação do índice de erodibilidade proposto por (Bastos, 1999), conforme a equação 1 .

horizontes B e C dos taludes da Vigilância Sanitária e da Ligação são apresentados na tabela 4. Na tabela 5 apresentam-se os resultados do grau de floculação e dispersão.

Os resultados da granulometria mostram que os horizontes B dos solos estudados, são constituídos de mais de $50 \%$ da fração argila, sendo classificados como solos argilosos. Nestes mesmos horizontes as concentrações de silte são baixas e similares, variando entre 6 e 7\%. Os horizontes $\mathrm{C}$ se mostraram menos argilosos e com maiores quantidades de silte em relação aos horizontes B. Sendo assim, os horizontes B são argilo-arenoso e os Horizontes C são siltoarenosos indicando haver uma diferença textural entre esses horizontes.

Os valores dos Índices de Atividades foram calculados de acordo com a definição de (Skempton, 1953).

Os resultados demonstraram que os horizontes dos solos estudados são compostos predominantemente por argilas inativas (IA $<0,75)$, com exceção do horizonte $\mathrm{C}$ da Vigilância Sanitária que apresentou índice de atividade de normal $(0,75<$ IA $<1,25)$. Observase que esses valores são concordantes com a mineralogia da fração argila, onde a presença de ilita somente é constatada no horizonte $\mathrm{C}$ da rua da ligação. 
As relações silte/argila obtidas nos horizontes estudados mostram que os horizontes B apresentam valores abaixo de 0,7 e os horizontes $\mathrm{C}$ acima deste limite. Este índice deve ser considerado como um bom índice indicativo de erodibilidade. Os horizontes B não são erodíveis, enquanto que os horizontes $\mathrm{C}$ são potencialmente erodíveis
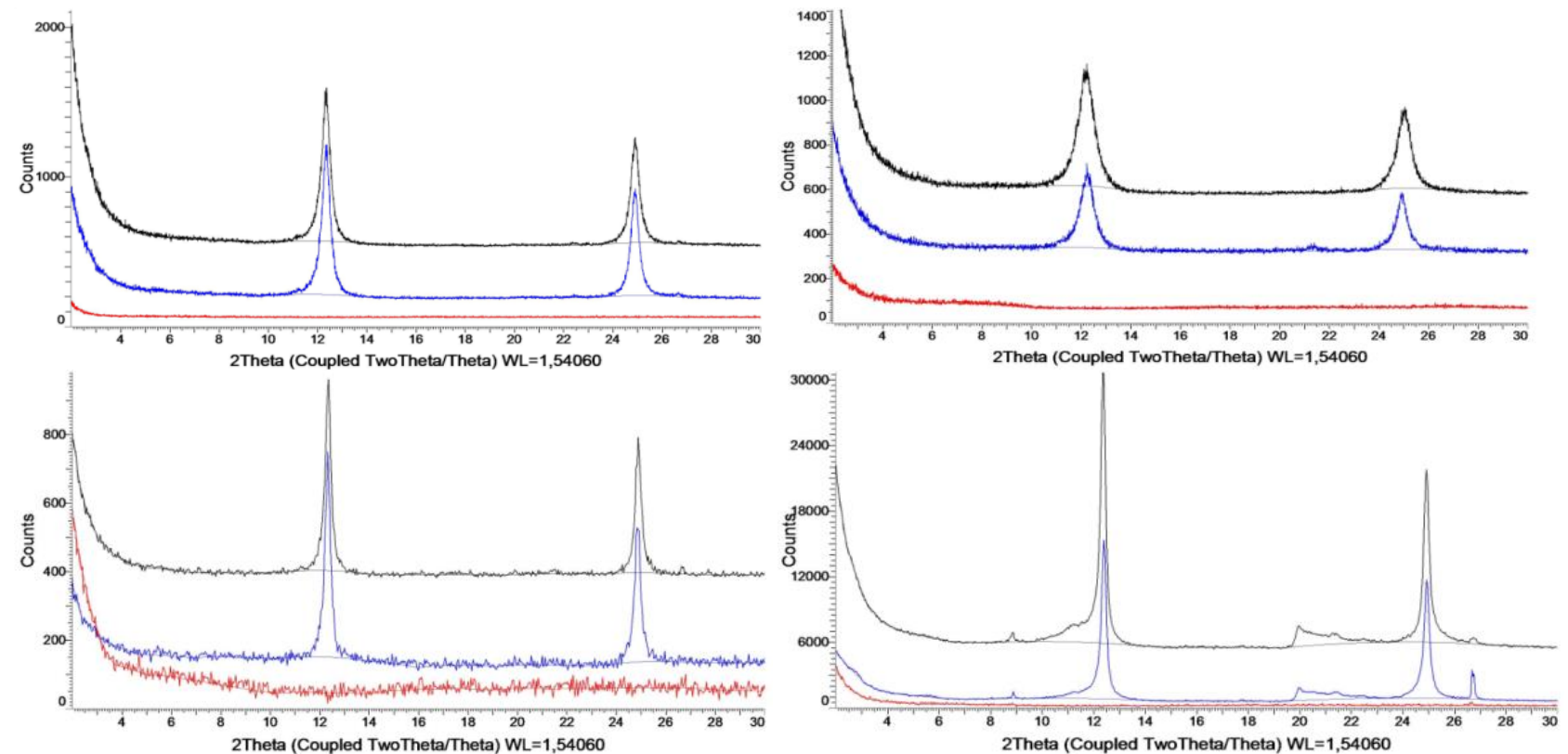

Figura 8 - A) Difratograma do horizonte B da Vigilância Sanitária, com a indicação dos picos de Caulinita (K). B) Difratograma do horizonte C da Vigilância Sanitária, com a indicação dos picos de Caulinita (K). C) Difratograma do horizonte B da Rua da Ligação, com a indicação dos picos de Caulinita (K). D) Difratograma do horizonte C da Rua da Ligação, com a indicação dos picos de Caulinita (K), traços de ilita - I(tr) e Quartzo (Q).

Tabela 4 - Caracterização Física dos horizontes de solos estudados, sendo que Argila (A), Silte (S), Finos Totais (FT) = Argila + Silte, Areia Fina (AF), Areia Média (AM), Areia Grossa (AG), Areia Total (AT), Pedregulho (P), Limite de Liquidez (LL), Limite de Plasticidade (LP), Índice de Plasticidade (IP), massa específica dos grãos ( $\rho$ s), umidade (W), massa específica aparente natural ( $\rho n)$, IA (Índice de Atividade), Sistema Unificado de Classificação de Solos (SUCS), CH-MH (argila de alta compressibilidade - silte de alta compressibilidade), MH (silte de alta compressibilidade), SC (areia argilosa) e SM-SC (areia argilosa - areia siltosa). Dados obtidos indiretamente através de correlações entre índices: porosidade $(\eta)$ e índice de vazios (e).

\begin{tabular}{|c|c|c|c|c|c|c|c|c|c|c|c|c|c|c|c|c|c|c|c|}
\hline \multirow{2}{*}{ Amostra } & \multicolumn{8}{|c|}{ Granulometria } & \multicolumn{3}{|c|}{$\begin{array}{c}\text { Limites de } \\
\text { Atterberg (\%) }\end{array}$} & \multicolumn{5}{|c|}{ Índices Físicos } & \multirow{2}{*}{ IA } & \multirow{2}{*}{$\begin{array}{l}\text { Silte/ } \\
\text { Argila }\end{array}$} & \multirow{2}{*}{ sucs } \\
\hline & $\mathbf{A}$ & $\mathbf{S}$ & FT & $\mathbf{A F}$ & $\mathbf{A M}$ & AG & $\mathbf{A T}$ & $\mathbf{P}$ & $\mathbf{L L}$ & LP & IP & $\begin{array}{c}\rho_{\mathrm{s}} \\
\left(\mathrm{g} / \mathrm{cm}^{3}\right)\end{array}$ & $\begin{array}{c}\mathrm{W} \\
(\%)\end{array}$ & $\underset{\left(\mathrm{g} / \mathrm{cm}^{3}\right)}{\rho_{\mathrm{n}}}$ & $\begin{array}{c}\eta \\
(\%)\end{array}$ & e & & & \\
\hline $\begin{array}{c}\text { Vig. San. } \\
\text { B }\end{array}$ & 56 & 6 & 62 & 9 & 16 & 11 & 36 & 2 & 55 & 27 & 28 & 2,68 & 19,9 & 1,82 & 43 & 0,76 & 0,5 & 0,11 & CH-MH \\
\hline $\begin{array}{l}\text { Vig. San. } \\
\text { C } \\
\end{array}$ & 15 & 38 & 53 & 8 & 21 & 12 & 41 & 6 & 58 & 41 & 17 & 2,62 & 19,6 & 1,81 & 41 & 0,72 & 1,13 & 2,53 & MH \\
\hline Ligação B & 56 & 7 & 63 & 4 & 14 & 16 & 34 & 3 & 64 & 33 & 31 & 2,53 & 20,6 & 1,95 & 35 & 0,56 & 0,55 & 0,12 & CH-MH \\
\hline Ligação C & 12 & 31 & 43 & 9 & 28 & 20 & 57 & 0 & 48 & 42 & 6 & 2,67 & 14,2 & 1,63 & 46 & 0,87 & 0,5 & 2,58 & SM-SC \\
\hline
\end{tabular}

Tabela 5 - Grau de floculação e de dispersão dos horizontes de solos analisados.

\begin{tabular}{c|c|c|c|c|c}
\hline \multicolumn{2}{c|}{ Amostra } & $\begin{array}{c}\text { Argila sem } \\
\text { dispersante (\%) }\end{array}$ & $\begin{array}{c}\text { Argila com } \\
\text { dispersante (\%) }\end{array}$ & $\begin{array}{c}\text { Grau de } \\
\text { Dispersão (\%) }\end{array}$ & $\begin{array}{c}\text { Grau de } \\
\text { Floculação (\%) }\end{array}$ \\
\hline \multirow{2}{*}{ Vigilância Sanitária } & Horizonte B & 17 & 56 & 30 & 70 \\
\cline { 2 - 7 } & Horizonte C & 0 & 15 & 0 & 100 \\
\hline \multirow{2}{*}{ Rua da Ligação } & Horizonte B & 21 & 56 & 37,5 & 62,5 \\
\cline { 2 - 7 } & Horizonte C & 0 & 12 & 0 & 100 \\
\hline
\end{tabular}

Os resultados dos limites de consistência possuem maiores índices de plasticidade que os mostraram que os horizontes $\mathrm{B}$, argilo-arenoso, horizontes $\mathrm{C}$, silto-arenoso. Comparando esses 
valores com a erodibilidade proposta por Meirelles (1967) nenhum desses horizontes são considerados fortemente erodíveis, entretanto observa-se que os horizontes $\mathrm{B}$ de ambos os perfis apresentam esses índices mais elevados que os horizontes C. Isso é um indicativo que os horizontes B apontam para uma menor erodibilidade que os horizontes $\mathrm{C}$.

De acordo com os resultados apresentados pela tabela 5, os horizontes pedológicos (B), possuem maior grau de dispersão das argilas e consequentemente menor grau de floculação em relação aos horizontes $\mathrm{C}$.

Os resultados apontaram grau de floculação de $100 \%$ para os horizontes $\mathrm{C}$, mostrando que os materiais desse horizonte, nas condições de campo, se comportam fisicamente como materiais granulares. As argilas destes horizontes, quando não submetidas ao dispersante, se comporta naturalmente como fração arenosa. Dessa forma fica claro que os arrastes de partículas em condições hídricas são favorecidas nos horizontes $\mathrm{C}$ dos perfis analisados. Esse dado também mostra a maior erodibilidade do solo saprolítico.

Analisando esses dados com a erodibilidade proposta por (Bastos, 1999) relacionado ao IP, verifica-se que dentre os horizontes estudados somente o horizonte $\mathrm{C}$ da Rua da Ligação apresenta valor considerado como material erodível.

Entretanto, destaca-se que nos dois perfis estudados há um decréscimo acentuada do IP entre os horizontes $\mathrm{B}$ e $\mathrm{C}$, portanto, pode-se supor que esse forte gradiente é indicativo que os horizontes $\mathrm{C}$ são potencialmente mais erodíveis que os horizontes $\mathrm{B}$ dos perfis estudados.

A tendência de aumento da erodibilidade com o decréscimo no teor de finos e no índice de plasticidade foi confirmada para solos tropicais africanos (Meireles, 1967) e para perfis de intemperismo de gnaisse da Via Dutra (Rego, 1978).

De acordo com Bastos (1999), o teor de finos, representado pela porcentagem passante na peneira \#200, está entre as propriedades físicas dos solos que melhor se relaciona com a erodibilidade. Segundo o autor, os solos de baixa erodibilidade apresentaram teor de finos acima de $55 \%$. Segundo esse autor, os horizontes B estudados não são erodíveis e os horizontes $C$ são erodíveis.

A classificação da erodibilidade dos horizontes de solo com base em índices de consistência, granulometria e índices físicos são exibidos nas tabelas 6 e 7 .

Tabela 6 - Erodibilidade dos horizontes do talude Vigilância Sanitária baseada em índices de consistência e granulometria, de acordo com autores com os parâmetros de analise que mais se adequaram aos resultados obtidos em laboratórios.

\begin{tabular}{c|c|c|c}
\hline Autor & Parâmetros de Análise & Vigilância Sanitária Horizonte B & Vigilância Sanitária Horizonte C \\
\hline Santos e Castro (1967) & LL e IP & Não potencialmente erodível & Potencialmente erodível \\
\hline Santos (2001) & IP & Boa resistência à erosão & Média resistência à erosão \\
\hline Bastos (1999) & Granulometria & Não potencialmente erodível & Potencialmente erodível \\
\hline Fragassi (2001) & Granulometria & Pouco erodível & Mais erodível \\
\hline Alcântara (1997) & IP e Granulometria & Baixa Erodibilidade & Média Erodibilidade \\
\hline
\end{tabular}

Tabela 7 - Erodibilidade dos horizontes do talude da Rua da Ligação baseada em índices de consistência e granulometria, de acordo com autores com os parâmetros de analise que mais se adequaram aos resultados obtidos em laboratórios.

\begin{tabular}{c|c|c|c}
\hline Autor & Parâmetros de Análise & Rua da Ligação Horizonte B & Rua da Ligação Horizonte C \\
\hline Santos e Castro (1967) & LL e IP & Não potencialmente erodível & Potencialmente erodível \\
\hline Santos (2001) & IP & Boa resistência à erosão & Baixa resistência à erosão \\
\hline Bastos (1999) & Granulometria & Não potencialmente erodível & Potencialmente erodível \\
\hline Fragassi (2001) & Granulometria & Pouco erodível & Mais erodível \\
\hline Alcântara (1997) & IP e Granulometria & Baixa Erodibilidade & Média Erodibilidade \\
\hline
\end{tabular}

Segundo IAEG (1979), através dos índices de plasticidade podemos classificar os solos conforme a sua plasticidade, sendo IP $<0$ (não plástico), $1<\mathrm{IP}<7$ (levemente plástico), $7<\mathrm{IP}$ $<17$ (moderadamente plástico), $17<$ IP $<35$ (altamente plásticos) e IP > 35 (extremamente plástico).
Diante disso, todos os horizontes $\mathrm{B}$ tem plasticidade alta, enquanto o horizonte $\mathrm{C}$ da Vigilância Sanitária possui plasticidade moderada e o horizonte $\mathrm{C}$ da rua da Ligação é levemente plástico. Novamente, segundo essa classificação, pode-se afirmar que os horizontes B são menos erodíveis que os horizontes C 
estudados pois apresentam maiores plasticidades.

A análise dos dados permite concluir que os horizontes B estudados não demonstram apresentar erodibilidade, enquanto os horizontes C (solos saprolíticos) apontam ter alto potencial de erodibilidade.

\section{Cisalhamento Direto}

A tabela 8 apresenta os parâmetros de resistência (coesão e ângulo de atrito), além do parâmetro $\Delta \mathrm{c}$, proposto por Bastos (1999), relacionados aos resultados dos ensaios de cisalhamentos na condição natural e inundado.

Os valores de coesão das amostras inundadas são significativamente menores que as na

umidade natural. Este fato demostra que a coesão aparente nos dois perfis estudados tem uma parcela considerável nesses valores. A perda de coesão desses materiais em ambientes inundados favorece ao processo erosivo devido a maior facilidade do arraste das partículas.

Em relação ao parâmetro $\Delta \mathrm{c}$, os resultados revelaram uma tendência dos solos saprolíticos (horizonte $\mathrm{C}$ ), em um mesmo perfil, apresentarem maior variação de coesão, com o aumento do grau de saturação, em relação aos horizontes pedológicos. Os dados mostram que há um gradiente significativo de $\Delta c$ entre os horizontes pedológicos (Horizonte B) e os solos saprolíticos (Horizonte C).

Tabela 8 - Parâmetros de resistência ao cisalhamento dos horizontes nas condições de umidade natural e inundada: $c_{\text {nat }}$ (coesão na umidade natural), $\varphi$ (ângulo de atrito na condição de umidade natural), $c_{\text {nat }}$ (coesão na condição inundada), $\varphi$ ' (ângulo de atrito na condição inundada) e $\Delta \mathrm{c}$ (variação da coesão nas condições natural e inundada, dada pela fórmula $\Delta \mathrm{c}$ $(\%)=\left(\mathrm{c}_{\text {nat }}-\mathrm{c}_{\text {inu }}\right) / \mathrm{c}_{\mathrm{nat}} \mathrm{X} 100$.

\begin{tabular}{|c|c|c|c|c|c|c|}
\hline \multicolumn{7}{|c|}{ Ensaio de Cisalhamento (kPa) } \\
\hline \multicolumn{2}{|c|}{ Amostra } & $\mathbf{C}_{\text {nat }}$ & $\varphi$ & $\mathrm{C}_{\text {inu }}$ & $\varphi ’$ & $\Delta C(\%)$ \\
\hline \multirow{2}{*}{ Vigilância Sanitária } & Horizonte B & 14,51 & 69,19 & 5,15 & 37,72 & 64,5 \\
\hline & Horizonte $\mathrm{C}$ & 72,44 & 24,59 & 8,38 & 26,69 & 88,43 \\
\hline \multirow{2}{*}{ Rua da Ligação } & Horizonte B & 26,63 & 41,88 & 5,22 & 46,86 & 80,4 \\
\hline & Horizonte C & 43,14 & 33,72 & 4,1 & 32,23 & 90,5 \\
\hline
\end{tabular}

\section{CONCLUSÕES}

O trabalho conclui que os taludes estudados apresentam fragilidades geotécnicas acentuadas, no qual os horizontes $\mathrm{C}$ apresentam maior potencialidade de erodibilidade que os horizontes $\mathrm{B}$, e devido a este fato, quando expostos tende a sofrer processos erosivos intensos no horizonte saprolítico, desestabilizando os horizontes sobrejacentes (horizontes B), e favorecendo os movimentos de massa.

As atividades de campo realizadas ao longo dos taludes estudados confirmaram o inadequado uso do solo, através de cortes verticais com objetivo de ampliar o espaço para construções diversas. Tais intervenções antrópicas aumentam a suscetibilidade dos materiais terrosos em relação aos processos erosivos.

As relações silte/argila e o grau de floculação obtidas nos horizontes estudados se mostraram como índices extremamente importantes em estudos de erodibilidade de solos. Sugere-se aplicar esses índices como complemento para determinar a erodibilidade de solos, destacando-se a sua grande simplicidade de obtenção.

Os resultados dos índices de Skempton classificou a fração argila como inativa em todos os horizontes, com exceção do horizonte $\mathrm{C}$ da Vigilância que foi apontado como argila normal. Esse resultado é bem relacionado com a mineralogia da fração argila, onde a caulinita foi o único argilomineral detectado nos solos estudados, com exceção do Horizonte $\mathrm{C}$ do talude da Rua da Ligação onde foram determinados adicionalmente à caulinita traços do argilomineral illita.

Os parâmetros de erodibilidade utilizados neste trabalho indicam que os solos saprolíticos (Horizonte C) apresentam um grande potencial de erodibilidade, enquanto os horizontes pedológicos (Horizonte B) apresentaram baixo potencial de erodibilidade.

Trabalhos de campo mostraram que o município de São João de Meriti-RJ é caracterizado por ocupações inadequadas em cortes de taludes, expondo os solos saprolíticos, caracterizados como de alta fragilidade sob o aspecto da erodibilidade.

Dessa forma, a erosão nos horizontes C acarreta na desestabilização dos horizontes pedológicos (Horizonte B) favorecendo os movimentos de massa. Situações que é bem frequente na região estudada, principalmente em 
períodos chuvosos.

Esse trabalho busca alertar às autoridades municipais quanto ao uso do solo urbano, em especial, para a necessidade de se evitar cortes profundos atingindo os horizontes saprolíticos que apresentam fragilidade quanto aos aspectos de erodibilidade que deflagram tombamento dos horizontes favorecendo escorregamentos.

\section{REFERÊNCIAS}

ABNT. Associação Brasileira de Normas Técnicas. NBR 6457: Amostras de Solo - Preparação para Ensaios de Compactação e Ensaios de Caracterização: método de ensaio. Rio de Janeiro: ABNT, 2016a.

ABNT. Associação Brasileira de Normas Técnicas. NBR 6459: Solo - Determinação do limite de liquidez: método de ensaio. Rio de Janeiro: ABNT, 2017a.

ABNT. Associação Brasileira de Normas Técnicas. NBR 6508: Determinação da Massa Específica dos Grãos: método de ensaio. Rio de Janeiro: ABNT, 1984.

ABNT. Associação Brasileira de Normas Técnicas. NBR 7180: Solo - Determinação do limite de plasticidade: método de ensaio. Rio de Janeiro: ABNT, 2016b.

ABNT. Associação Brasileira de Normas Técnicas. NBR 7181: Solo - Análise granulométrica: método de ensaio. Rio de Janeiro: ABNT, 2017b.

ABNT. Associação Brasileira de Normas Técnicas. NBR 9604: Abertura de poço e trincheira de inspeção em solo, com retirada de amostras deformadas $e$ indeformadas: procedimento. Rio de Janeiro: ABNT, 2016c.

ABNT. Associação Brasileira De Normas Técnicas. NBR 9813: Solo: Determinação da massa específica aparente in situ, com emprego de cilindro de cravação: Método de ensaio. Rio de Janeiro: ABNT, 2016d.

ALCÂNTARA, M.A.T. Aspectos geotécnicos da erodibilidade de solos. São Carlos, 1997. 128p. Dissertação (Mestrado), Escola de Engenharia de São Carlos - Universidade de São Paulo.

ALMEIDA, F.F.M. The system of continental rifts bordering the Santos Basin. Anais da Academia de Ciências e Letras, Rio de Janeiro, 58 (suplemento), p. 15-26, 1976.

AMERICAN SOCIETY FOR TESTING AND MATERIALS ASTM. D3080: Standard Test Method for Direct Shear Test of Soils Under Consolidated Drained Conditions. 6p., 1990.

BASTOS, C.A.B. Estudo geotécnico sobre a erodibilidade de solos residuais não saturados. Porto Alegre. 1999. 303p. Tese (Doutorado), Escola de Engenharia Civil- Universidade Federal do Rio Grande do Sul.

BETTS, H.; BASHER, L.; DYMOND, J.; HERZIG, A.; MARDEN, M.; PHILLIPS, C. Development of a landslide component for a sediment budget model. Environmental Modelling \& Software, v. 92, p. 28-39, 2017.

BRASIL. Ministério da Integração Nacional. Secretaria Nacional de Defesa Civil. Banco de dados e registros de desastres: sistema integrado de informações sobre desastres - S2ID. 2013. Disp. em: <http://s2id.mi.gov.br/>. Acesso em: 07 jan. 2018.

CHEN, Y.; CHANG, K.; LEE, H.; CHIANG, S. Average landslide erosion rate at the watershed scale in southern Taiwan estimated from magnitude and frequency of rainfall. Geomorphology, v. 228, n. 1, p. 756-764, 2015.

DANTAS, M.E. Geomorfologia do Estado do Rio de Janeiro, In: Estudo Geoambiental do Estado do Rio de Janeiro. Brasília/CPRM. Mapa. CDROM. 63p., 2000.

EMPRESA BRASILEIRA DE PESQUISA AGROPECUÁRIA EMBRAPA. Sistema brasileiro de classificação de solos. $3^{\mathrm{a}}$ Ed. Brasília, DF: Embrapa, 353 p., 2013.

EMPRESA BRASILEIRA DE PESQUISA AGROPECUÁRIA ENBRAPA. Manual de métodos de análise de solo. 3ed. revisada e ampliada. Rio de Janeiro, Embrapa, 573 p. 2017

ERNANI, P.R. Química dos solos e disponibilidade de nutrientes. Lages: Paulo Ernani, 230 p., 2008.

FAN, X.; ZHAN, W.; DONG, X.; VAN WESTEN, C.; XU, Q.;
DAI; L.; YANG, Q.; HUANG, R.; HAVENITHD, H. B. Analyzing successive landslide dam formation by different triggering mechanisms: the case of the Tangjiawan landslide, Sichuan, China. Engineering Geology, v. 243, p. 128-144, 2018.

FRAGASSI, P.F.M. Estudo da erodibilidade dos solos residuais de gnaisse da Serra de São Geraldo e de Viçosa (MG). Viçosa, 2001. 119 p. Dissertação de Mestrado, Programa de Pós-graduação em Engenharia Civil, Universidade Federal de Viçosa.

FURUYA, G.; SASSA, K.; HIURA, H.; FUKUOKA, H. Mechanism of creep movement caused by landslide activity and underground erosion in crystalline schist, Shikoku Island, southwestern Japan. Engineering Geology, v.. 53, n. 3-4, p. 311-325, 1999.

IAEG - INTERNACIONAL ASSOCIATION OF ENGINEERING GEOLOGY. Commission "Engineering Geological Mapping" Classification of Rocks and Soils for Engineering Geological Mapping Part 1: Rock and Soil Materials. Bulletin of the International Association of Engineering Geology. Krefeld, v. 19, p. 364-371, 1979.

IBGE - Instituto Brasileiro de Geografia e Estatística. Censo Demográfico 2010. Rio de Janeiro: IBGE, 2010. Disp. em: <http://censo2010.ibge.gov.br>.

IBGE - Instituto Brasileiro de Geografia e Estatística. Manual técnico de pedologia. 2ed. Rio de Janeiro, IBGE, 316 p., 2007.

IBGE - Instituto Brasileiro de Geografia e Estatística. Mapa de clima do Brasil. Rio de Janeiro: IBGE, Escala 1:5.000.000. 2002. Disp. em: < https://mapas.ibge.gov.br/tematicos.html>.

JACKSON, M.L. Soil chemical analysis: advanced course. Madison, University of Wisconsin, 895 p., 1969.

MEHRA, O.P.; JACKSON, M.L. Iron oxide removal from soils and clays by a dithionite-citrate system buffered with sodium bicarbonate. In: CLAYS \& CLAY MINERAL CONFERENCE, 7, London, 1960. Anais... London, 1960, p. 317-327.

MEIRELES, J.M.F. Erosão de taludes de estradas. In: JORNADAS LUSO-BRASILEIRAS DE ENGENHARIA CIVIL, 2, Rio de Janeiro/São Paulo, 1967. Anais... Rio de Janeiro/São Paulo, 1967, p. 204-211.

MOREIRA, R.F. \& POLIVANOV, H. Potencial Erosivo de Perfil de Solo de Talude de Corte através de Ensaios de Inderbitzen. 2018. doi: 10.12957/geouerj.2018.32158.

MUNSELL COLOR COMPANY. Munsell Color Soil Charts. Baltimore, Kollmorgen 456 Corporation, 22 p., 1946.

PREFEITURA MUNICIPAL DE SÃO JOÃO DE MERITI. Plano Municipal de Redução de Riscos (PMRR). PROGRAMA "APOIO À PREVENÇÃO E ERRADICAÇÃO DE RISCOS EM ASSENTAMENTOS PRECÁRIOS", 1155 p., 2013.

RADBRUCH-HALL, D.H. \& VARNES D.J. Landslides Cause and effect. Bulletin of the International Association of Engineering Geology, 1976.

REGO, J.J.V. Erosão superficial em taludes de corte em solo residual de gnaisse. Rio de Janeiro, 1978. 125p. Dissertação (Mestrado em Ciências), Universidade Federal do Rio de Janeiro.

SANTOS, C.A. Comportamento hidrológico superficial, subsuperficial e a erodibilidade dos solos da região de Santo Antônio do Leite, distrito de Ouro Preto - Minas Gerais. Ouro Preto, 2001. 107 p. Dissertação (Mestrado), Universidade Federal de Ouro Preto.

SANTOS, M.P. \& CASTRO, E. Estudo sobre erosão em taludes 
de estradas. In: JORNADAS LUSO- BRASILEIRAS DE ENGENHARIA CIVIL, 2, Rio de Janeiro/ São Paulo, 1967. Anais...Rio de Janeiro/São Paulo, p. 220 -241, 1967.

SILVA, L.C. \& CUNHA, H.C. DA S. Geologia do Estado do Rio de Janeiro: texto explicativo do mapa do Estado do Rio de Janeiro, Brasília, CPRM, 2001.

SKEMPTON, A.W. The Colloidal Activity of Clays, Proceedings. In: ICSMFE, 3, Zurique, 1953. Anais... Zurique, 1953, p.57-61.
WANG, F.; OKEKE, A.C.U.; KOGURE, T.; SAKAI, T.; HAYASHI, $\mathrm{H}$. Assessing the internal structure of landslide dams subject to possible piping erosion by means of microtremor chain array and self-potential surveys. Engineering Geology, v. 234, p. 11-26, 2018.

Submetido em 16 de janeiro de 2019 Aceito em 6 de dezembro de 2019 